\title{
Analisis dan Perancangan Software Pengukuran Metrik Skala dan Kompleksitas Database Relasional
}

\author{
Mochammad Rizqy Pratamaa ${ }^{1, *}$, Muhammad Ainul Yaqin², Bunga Cahyaning Untaria ${ }^{3}$, Dwi Zulva \\ Uliunuha $^{4}$, Abd. Charis Fauzan ${ }^{5}$ \\ 1,2,3,4 Jurusan Teknik Informatika, Universitas Islam Negeri Maulana Malik Ibrahim, Indonesia \\ ${ }^{5}$ Program Studi Ilmu Komputer, Universitas Nahdlatul Ulama Blitar, Indonesia \\ 118650107@ student.uin-malang.ac.id, ${ }^{2} 18650108 @$ student.uin-malang.ac.id, ${ }^{3} 18560120 @$ student.uin-malang.ac.id, \\ 4yaqinov@ti.uin-malang.ac.id; 5 abdcharis@ unublitar.ac.id \\ * corresponding author
}

INFO ARTIKEL

Sejarah Artikel

Diterima: 20 Desember 2019

Direvisi: 11 April 2020

Diterbitkan: 30 Agustus 2020

Kata Kunci

Metriks Skala

Kompleksitas

Database Relational

\section{ABSTRAK}

Database relasional merupakan database yang di dalamannya terdapat tabel-tabel yang berhubungan antar satu tabel dengan yang lainnya. Pada database relasi terdapat kompleksitas database relasional. Untuk dapat mengetahui nilai kompleksitas database relational, diperlukan perhitungan kompleksitas database terlebih dahulu. Pada perhitungan kompleksitas database cara perhitungannya cukup rumit apabila menggunakan perhitungan manual karena kita harus membandingkan dengan database lain, selain itu perhitungan manual juga membutuhkan waktu yang lama. Oleh karena itu, kami melakukan penelitian yang bertujuan untuk menghasilkan suatu software yang dapat menentukan nilai kompleksitas sebuah database dengan menggunakan metrik skala. Untuk menentukan nilai kompleksitas database di berikan bobot pada tiap tabel, kolom, primary key, foreign key, secondary key, tipe data, lebar data, relation yang kemudian di hitung dengan menggunakan rumus yang telah kami tentukan. Dengan penelitian yang kami lakukan dihasilkan sebuah perancagan software untuk melakukan pengukuran kompleksitas database dengan cara memasukkan query database tersebut. Dengan di buatnya software ini di harapkan mampu meringankan kerja kita ketika di haruskan untuk mengukur kompleksitas database relasional.

\section{PENDAHULUAN}

Database Relasional merupakan jenis database management system yang terbaru[1]. Database relasional ini menyajikan bagan skema dimana antar table itu memiliki hubungan atau relasi dengan table yang lainnya. Pada database relational terdapat nilai kompleksitas relational database. Saat ini untuk mengetahui nilai kompleksitas database masih di lakukan secara manual, dikarenakan belum ada software yang berfungsi untuk mengukur nilai kompleksitas database. Sebuah software pastilah memerlukan database guna menyimpan data dalam sebuah software. Bisa dibilang database ini merupakan salah satu basic atau dasar dalam pembuatan sebuah software[2]. Tetapi pada faktanya kompleksitas database sering diabaikan, pengukuran seringkali lebih memfokuskan pada perangkat lunak nya saja dan tidak pada database nya[3]. Oleh karena itu, sangat penting mengukur kompleksitas suatu relasional database. Proses penghitungan nilai kompleksitas database tersebut harus di lakukan dengan pembandingan secara manual yang prosesnya sangat panjang dan membutuhkan waktu yang lama. Untuk mengatasi permasalahan yang ada penulis 
melakukan penelitian ini guna membuat analisa dan perancangan software yang berfungsi untuk menentukan nilai kompleksitas database dengan menggunakan metrik skala.

Metrik merupakan pengukuran yang dilakukan sehingga suatu subjek dapat diketahui perbedaannya dalam jumlah atau derajat. Variabel yang diukur menggunakan skala interval dan ratio umumnya merupakan variabel metrik. Metrik yang digunakan dalam paper ini merupakan jenis metrik kompleksitas, dimana metrik kompleksitas ini merupakan jenis metrik yang masih berada pada proses pengajuan. Metrik kompleksitas ini difokuskan untuk mengontrol, memprediksi, memahami dan juga meningkatkan pengembangan yang ada pada database serta perawatan terhadap sebuah proyek[4].

Penggunaan matrik skala ini akan memberikan nilai pada tiap masing-masing bagian penyusun database relasional sehingga nantinya pada software ini kita hanya perlu memasukkan query dari database tersebut untuk mengetahui nilai kompleksitasnya. Dengan di buatnya perancangan software ini penulis berharap nantinya akan memudahkan pengguna yang ingin melakukan pengukuran database agar mereka tidak perlu melakukan banyak pembandingan antar database[5]. Untuk melakukan perancangan software ini penulis menggunakan metode waterfall untuk penentuan bobot dari bagian penyusun database yang kemudian akan di gunakan pada perumusan nilai kompleksitas database.

Penelitian terdahulu hanya membahas sebatas pada teori dalam pengukuran kompleksitas database dan belum menyentuh pada software yang dapat mengukur kompleksitas relasional database. Pada penelitian Calero terdapat dua metrik database yang diidentifikasi yaitu kolom dan juga table[2]. Adapun penelitian oleh Pavlic yang mengidentifikasikan metrik database yakni kolom, primary key, foreign key, secondary key, dan juga index[6]. Dan belum lama ini terdapat sebuah penelitian yang dilakukan oleh Taufiq mengidentifikasi metrik database relasional secara lengkap yaitu table, relasi, kolom, primary key, foreign key, secondary key, index, tipe data, lebar data, dan juga jenis relasi[4]. Adapun pada paper ini akan mengidentifikasi metrik database berupa table, relasi, kolom, primary key, foreign key, secondary key, index, tipe data, lebar data, relasi one to one, one to many, dan many to many. Pada paper ini, kami menambahkan beberapa jenis metrik database baru yang belum ada pada penelitian sebelumnya yaitu relasi one to one, one to many, dan juga many to many. Dan pada penelitian ini, kami sudah menyentuh pada perancangan software yang dapat mengukur kompleksitas sebuah relasional database.

\section{METODE}

Pada analisis dan perancangan software menggunakan metrik skala dan kompleksitas database relasional, kami menggunakan Metode Waterfal. Metode ini kami pilih karena tahapan pada metode ini runtun dari satu proses ke proses selanjutnya, serta banyaknya kasus serupa yang menggunakan metode ini[7]. Adapun tahapan metode waterfall dapat dilihat pada Gambar 1.

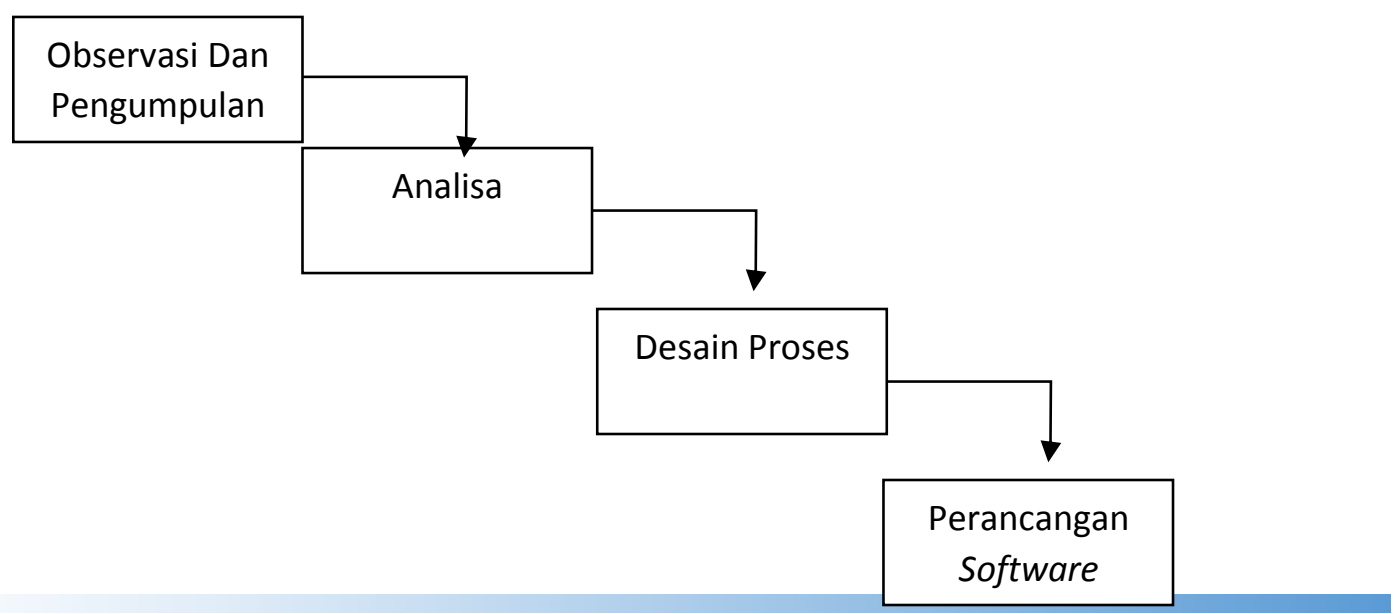




\section{Observasi dan Pengumpulan Data}

Gambar 1. Metode waterfall

Pada tahap ini, penulis melakukan studi literatur pada jurnal ilmiah, artikel, dan penelitian-penelitian sebelumnya yang berkaitan dengan judul penelitian kami. Pada tahap ini kami juga mengumpulkan data yang akan kami observasi dan yang akan di gunakan sebagai penunjang pada tahapan berikutnya.

\section{Analisa}

Pada tahap ini, penulis melakukan analisa dengan menggunakan metode analisa semiotik dan analisa korelasi. Analisa semiotik kami gunakan untuk mengetahui bagianbagian penyusun database relasional. Analisa korelasi yang di gunakan untuk mengetahui hubungan variabel, analisa ini kami gunakan untuk mengetahui kondisi relasi dari suatu database. Dari metode analisa ini di dapatkan tabel, kolom, tipe data, lebar data, primary key, foreign key, secondary key dan juga index yang merupakan bagian-bagian dari penyusun database.

\section{Desain Proses}

Pada tahap ini penulis melakukan proses perumusan dari informasi yang telah kami dapatkan dari tahap sebelumnya, tahapan ini terbagi menjadi beberapa bagian:

1. Identifikasi metrik

Pada tahap ini, penulis melakukan identifikasi dengan menggunakan metode GQM. Pada metode ini penulis akan merepresentasikan bagian-bagian penyusun database relasional yang yang dimulai dari mendesain top-levels goals, kemudian dibuatkan serangkaian pertanyaan untuk tiap goal dimana tiap pertanyaan akan dijawab jika goal tercapai[8]. Adapun hasil dari tahap ini dapat dilihat pada Tabel 1.

Tabel 1. Identifikasi metrik

\begin{tabular}{|l|l|}
\hline Question & Apa yang membentuk database relasional? \\
\hline Metrics & Tabel, relasi \\
\hline Question & Apa yang membentuk sebuah tabel? \\
\hline Metrics & Baris, kolom \\
\hline Question & Apa yang membentuk kolom? \\
\hline Metrics & $\begin{array}{l}\text { Tipe data, lebar data, primary key, foreign key, secondary } \\
\text { key, index }\end{array}$ \\
\hline Question & Apa saja jenis relasi? \\
\hline Metrics & One to one, one to many, many to many \\
\hline
\end{tabular}

2. Representasi metrik pada tree

Pada tahap ini, penulis mencoba merepresentasikan hasil dari identifikasi metrik dengan menggunakan metode tree[9]. Pada motode tree ini terdapat node dan edge. Node pada tree merepresentasikan metrik yang di dapat dari identifikasi metrik. Dan Edge merupakan representasi posisi node yang kemudian pada metode berikut digunakan untuk menentukan formulasi metrik. Adapun hasil dari tahap ini dapat dilihat pada Gambar 2. 


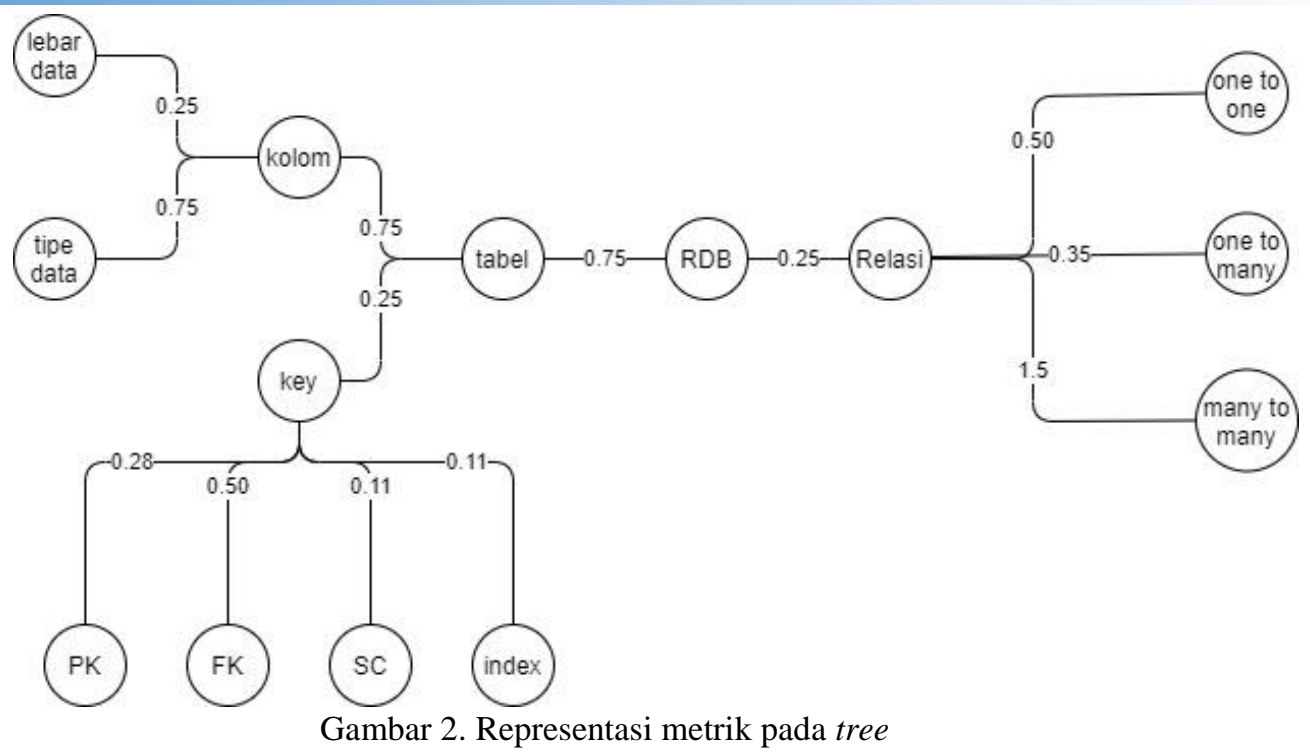

3. Formulasi metrik

Pada tahap ini, penulis melakukan formulasi metrik dengan menggunakan metode AHP. Dengan menggunakan metode AHP maka dilakukan pembandingan dari tiap bagian-bagian yang terdapat pada database relasional[10]. Adapun hasil dari pembandingan tersebut dan representasi dari metrik pada tree maka diperoleh hasil seperti yang terdapat pada Tabel 2. Untuk hasil pembandingan tipe data dapat dilihap pada Tabel 3 .

Tabel 2. Pembobotan metrik pada database relasional

\begin{tabular}{|l|l|}
\hline \multicolumn{1}{|c|}{ Metrik } & \multicolumn{1}{c|}{ Bobot } \\
\hline Tabel & 0.75 \\
\hline Kolom & 0.75 \\
\hline Tipe data & 0.75 \\
\hline Panjang data & 0.25 \\
\hline Key & 0.25 \\
\hline Primary key & 0.28 \\
\hline Foreign key & 0.50 \\
\hline Secondary key & 0.11 \\
\hline Index & 0.11 \\
\hline Relasi & 0.25 \\
\hline One to one & 0.50 \\
\hline One to many & 0.35 \\
\hline Many to many & 0.15 \\
\hline
\end{tabular}

Tabel 3. Bobot tipe data

\begin{tabular}{|c|l|c|}
\hline Kelompok & \multicolumn{1}{|c|}{ Tipe Data } & Bobot \\
\hline 1. & Bit & 0.01 \\
\hline 2. & Tinyint, year & 0.06 \\
\hline 3. & Smallint & 0.11 \\
\hline 4. & Char, binary, tinytext, tinyblob & 0.12 \\
\hline 5. & Text, blob, varchar, varbinary & 0.16 \\
\hline 6. & Mediumint, time & 0.17 \\
\hline 7. & Int, float, timestamp & 0.22 \\
\hline 8. & Mediumtext, mediumblob & 0.24 \\
\hline
\end{tabular}




\begin{tabular}{|c|l|c|}
\hline 9. & $\begin{array}{l}\text { Begint, double, decimal, real, numeric, datetime, } \\
\text { time }\end{array}$ & 0.44 \\
\hline 10. & Longtext, longblob & 0.48 \\
\hline
\end{tabular}

4. Formulasi Rumus kompleksitas database

Pada tahap ini, penulis melakukan formulasi rumus kompleksitas database. Perumusan ini di dapat dari tahap-tahap sebelumnya perumusan awalnya di dapat dari representasi metrik pada tree, untuk pembobotannya di dapat dari metode AHP. Dari implementasi metode-metode sebelumnya maka di dapat formulasi seperti yang terdapat pada perumusan 1 sampai dengan 5 . Terdapat sedikit perbedaan dari formula yang sudah diajukan sebelumnya oleh Taufiq[4]. Pada paper ini formula ditambahkan jenis relasi many to many, dimana pada formula sebelumnya tidak ada.

Untuk menghitung nilai relasional database yang langkah pertama adalah harus di hitung adalah Relation complecity yang rumusnya terdapat pada perumusan ke-5. Langkah ke dua, menghitung Key complecity yang rumusnya terdapat pada perumusan ke-4. Langkah ke tiga, menghitung Column complecity yang rumusnya terdapat pada perumusan ke-3. Langkah ke empat, menghitung Table complecity yang rumusnya terdapat pada perumusan ke-2. Langkah ke lima, menghitung Database complecity yang rumusnya terdapat pada perumusan ke-1.

$$
\begin{array}{ll}
\mathrm{DC} & =0.75 \sum \mathrm{TC}+0.25 \sum \mathrm{RC} \\
\mathrm{TC} & =0.75 \sum \mathrm{ColC}+0.25 \sum \mathrm{keyC} \\
\mathrm{ColC} & =0.75 \sum \mathrm{DT}+0.25 \mathrm{DW} \\
\mathrm{KeyC} & =((0.28) . \mathrm{PK}+(0.5) . \mathrm{FK}+(0.11) . \mathrm{SK}+(0.11) . \text { Index }) \\
\mathrm{RC} & =0.5 \sum \mathrm{R} 1: 1+0.35 \sum \mathrm{R} 1: \mathrm{M}+0.15 \sum \mathrm{RM}: \mathrm{M}
\end{array}
$$

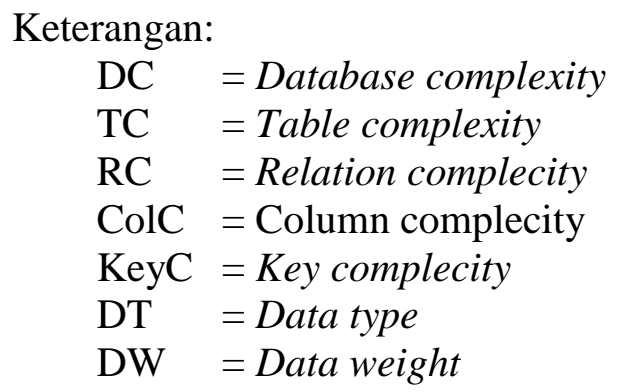

$$
\begin{array}{ll}
\mathrm{PK} & =\text { Primary key } \\
\mathrm{FK} & =\text { Foreign } k e y \\
\mathrm{SK} & =\text { Secondary } k e y \\
\mathrm{R} 1: 1 & =\text { Relation } \text { one to one } \\
\mathrm{R} 1: \mathrm{M} & =\text { Relation one to many } \\
\mathrm{RM}: \mathrm{M} & =\text { Relation many to many }
\end{array}
$$

\section{Perancangan Software}

Pada tahap ini, penulis melakukan perancangan sofware yang berfungsi untuk menentukan nilai kompleksitas suatu database dengan menggunakan metrik skala. Input yang di gunakan pada software ini adalah query dari database tersebut. Output dari software ini berupa nilai dari kompleksitas database tersebut. Untuk lebih lengkapnya metode perancangan software ini akan di bahas pada bagian hasil dan pembahasan.

\section{HASIL DAN PEMBAHASAN}

\section{Analisis Kebutuhan}

Dari analisis kebutuhan software pengukukan metrik skala kompleksitas relasional database dalam pembuatannya membutuhkan software lain yaitu Java, untuk membangun software baru dengan mengimplementasikan metrik skala di dalam programnya, sedangkan yang dibutuhkan sebagai input merupakan sebuah query $S Q L$ yang di dalamnya terdapat tabel berelasi agar nantinya bisa diproses oleh program yang telah dibuat pada software Java 
dan menghasilkan sebuah metrik yang merepresentasikan volume kompleksitas sebuah relasional database.

\section{Identifikasi Jenis-Jenis Relasi}

Terdapat tiga jenis relasi dalam database, yaitu one to one, one to many, dan juga many to many. Untuk mengidentifikasi jenis relasi database ini adalah dengan membandingkan ketiga query $S Q L$ dan menyimpulkan perbedaan dari ketiga query $S Q L$ tersebut. Dari Analisa yang dilakukan didapatkan cara untuk mengidentifikasi ketiga jenis relasi dari query $S Q L$. Relasi one to one : relasi jenis ini dalam query $S Q L$ memiliki 2 tabel dimana pada setiap table tersebut memiliki primary key dan juga foreign key. Terdapat query relasi dimana setiap primary key pada table, akan menuju ke foreign key pada tiap table itu juga. Yang membedakan relasi jenis ini dengan relasi lain berdasarkan kata dan juga karakter adalah terdapat 2 kata constraint pada relasi ini. Jadi dengan demikian didapatkan rumus kondisi untuk relasi jenis ini adalah "constraint" $==2$. Adapun Query $S Q L$ database dengan Relasi one to one dapat dilihat pada Gambar 3.
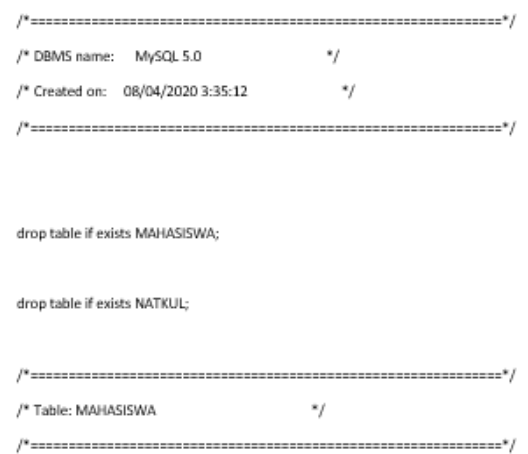

create table MAHASISWA

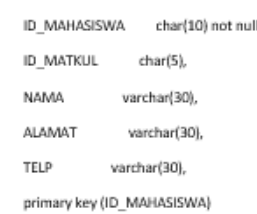

primary key (ID_MAHASISWA)

\begin{tabular}{|c|c|}
\hline$/ *$ Table: NATKUL & $\%$ \\
\hline
\end{tabular}

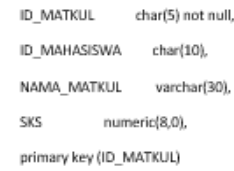

):

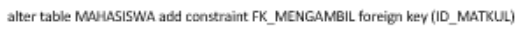

references NATKUL ID_ MATKUL) on delete restrict on update restrict;

alter table NATKUL add constraint FK_MENGAMBIL2 fareign Key (ID_MNMASISWA

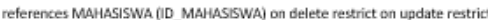

Gambar 3. Query SQL database dengan Relasi 1:1

Relasi one to many: relasi jenis ini dalam query $S Q L$ memiliki 2 tabel dimana pada setiap table tersebut memiliki primary key tetapi hanya satu table saja yang memiliki foreign key. Terdapat query relasi dimana table yang memiliki primary key tanpa foreign key akan menuju pada table yang memiliki foreign key. Yang membedakan relasi jenis ini dengan relasi lain berdasarkan kata dan juga karakter adalah terdapat 1 kata constraint saja pada relasi ini. Jadi dengan demikian didapatkan rumus kondisi untuk relasi jenis ini adalah "constraint" == 1. Adapun Query SQL database dengan Relasi one to many dapat dilihat pada Gambar 4. 

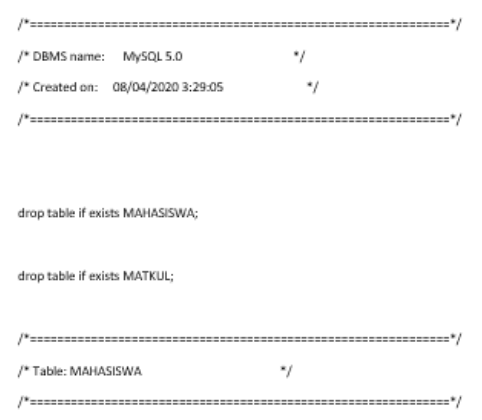

create table MAHASISWA

1

ID_MAMASISWA char(10) not null,

NAMA varchar(30).

ALAMAT varchar(30),

TELP varchar(30),

primary key (10_MAHASISWA)

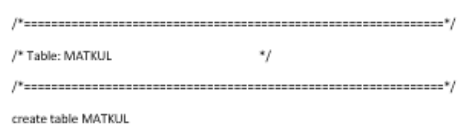

ID_MATKUL Char(5) not null,

ID_MAMASISWA char (10),

NAMA_MATKUL varchar(30)

sks numeric(8,0),

primary key (ID_MATKUL)

l:

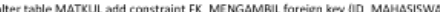

I

Gambar 4. Query SQL database dengan Relasi 1:M

Relasi many to many : relasi jenis ini dalam query $S Q L$ memiliki 3 tabel yang mana 1 tabel tambahannya merupakan table yang keberadaannya ditimbulkan oleh relasi itu sendiri. 1 tabel tambahan tersebut berisi primary key yang ada pada setiap table lainnya. Pada relasi jenis ini terdapat 2 query relasi. Yang membedakan relasi jenis ini dengan relasi lain bedasarkan kata dan juga karakter adalah terdapat 2 kata constraint. Pembeda lain dari relasi ini dengan relasi yang lain adalah terdapat satu table dimana table tersebut berisikan 2 primary key. Jadi dengan demikian didapatkan rumus kondisi untuk relasi jenis ini adalah "constraint" = $=2$ \&\& "TABLE" + " " + "(" + "PRIMARY" > 1 + ")" . Adapun Query SQL database dengan Relasi many to many dapat dilihat pada Gambar 5.
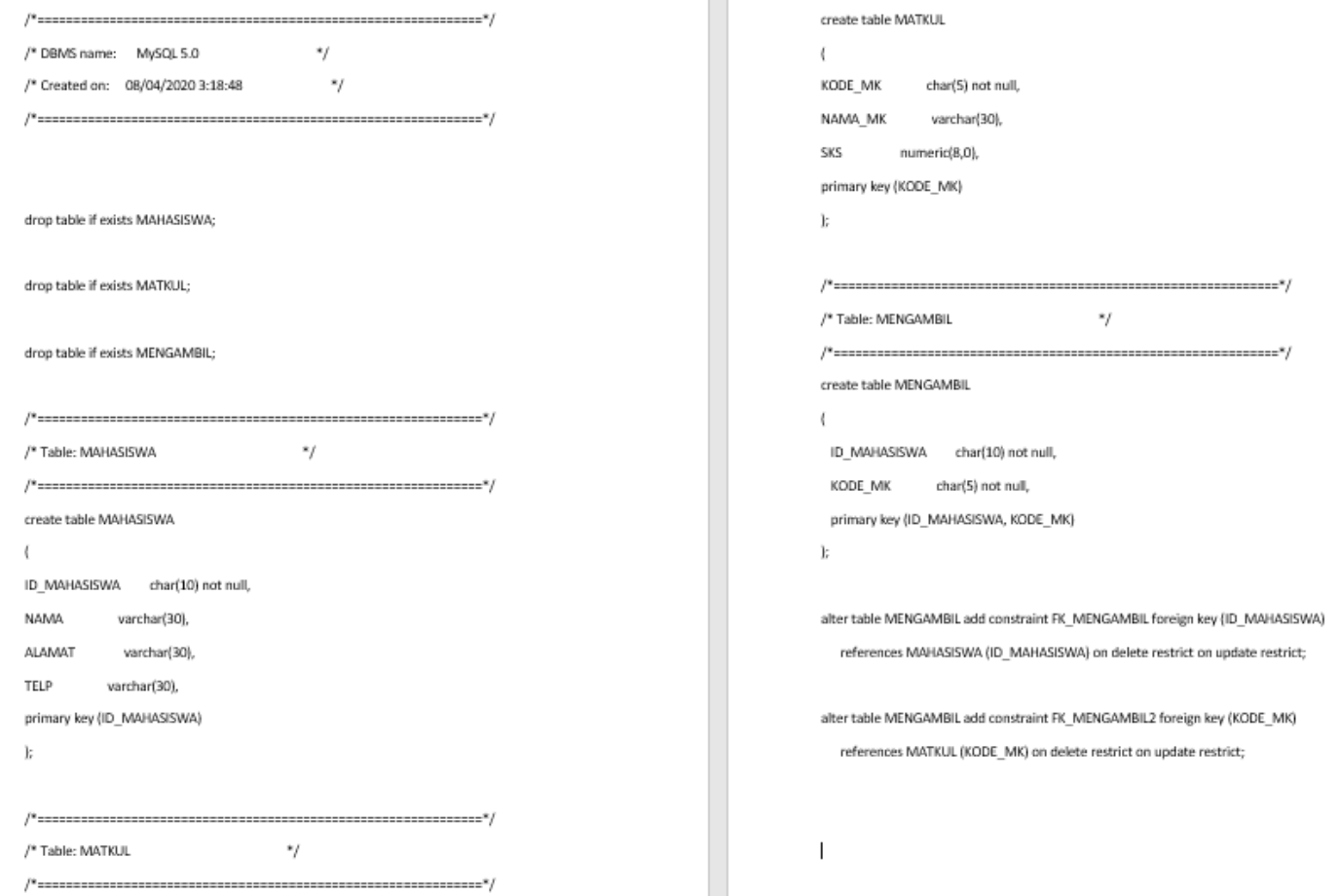

Gambar 5. Query SQL database dengan Relasi M:M 


\section{Use Case}

Adapun kebutuhan fungsional dari Perancangan software ini yang akan di transformasikan ke dalam bentuk Use Case, dimana Use Case ini akan menggambarkan apa saja yang dapat dilakukan dan didapatkan oleh user dalam system ini. Skenario use case akan menjelaskan bagaimana perilaku pengguna terhadap system. Adapun use case dari perancangan software ini dapat dilihat pada Gambar 6.
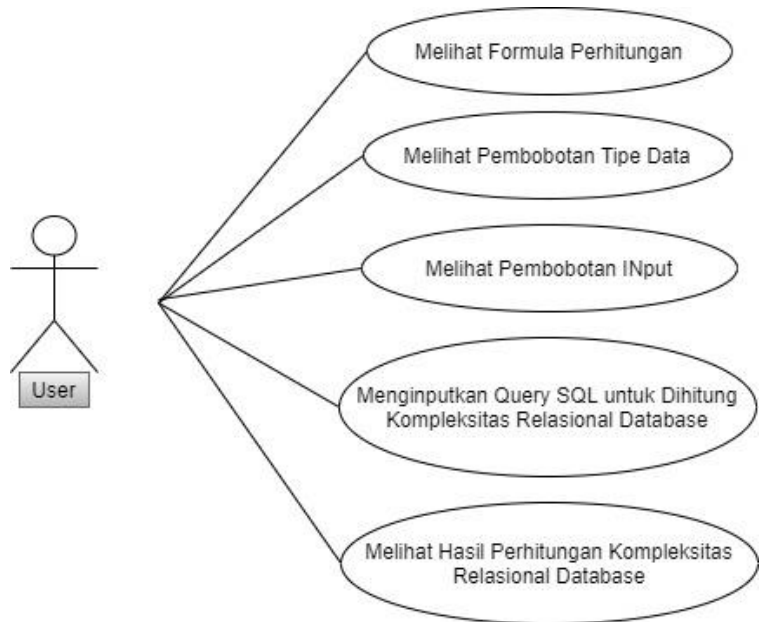

Gambar 6. Use Case Sistem Perhitungan Kompleksitas Relasional Database

\section{Class diagram}

Class diagram merupakan representasi dari alur program yang telah diprogram pada Java, agar mudah dibaca dan mudah dipahami. Dengan merepresentasikan program ke dalam class diagram dapat dibuat bagan yang jelas dan rinci dengan memperhatikan kode yang spesifik apa saja yang dibutuhkan suatu progran sehingga mampu mengimplementasikannya ke struktur yang digambarkan. Adapun class diagram dari perancangan software ini dapat dilihat pada Gambar 7.

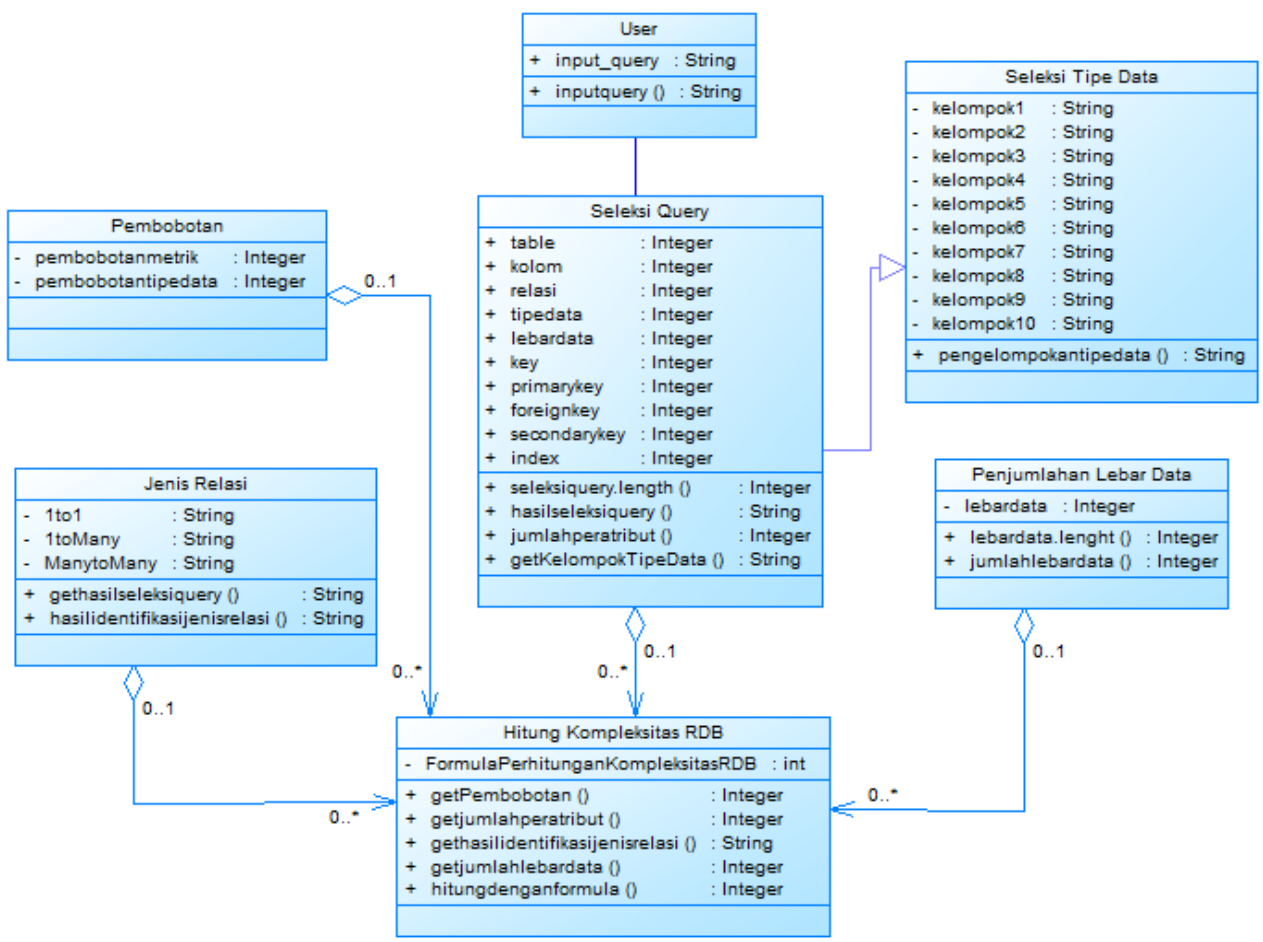

Gambar 7. Class diagram Perhitungan Kompleksitas Relasional Database 


\section{Flowchart}

Flowchart menjelaskan bagaimana system ini berjalan yang mana di transformasikan dalam bentuk diagram alur. Terdapat beberapa alur system yang akan dibahas dalam pembahasan ini, yaitu diagram alur kasus penggunaan system, diagram alur kasus seleksi query SQL, diagram alur kasus seleksi dan perhitungan tipe data dan terakhir adalah diagram alur kasus perhitungan kompleksitas relasional database.

Pada diagram alur kasus penggunaan system ini dijelaskan tentang bagaimana user akan bisa menggunakan system ini. Pada halaman awal, akan disajikan 4 pilihan menu yang mana itu adalah formula, input weight, data type weight dan counting DB. Menu formula akan menuju ke halaman dimana terdapat formula yang digunakan untuk menghitung kompleksitas database dalam system ini. Menu input weight akan menuju ke halaman dimana ada table yang menyajikan pembobotan dari tiap metrik database. Menu data type weight akan menuju ke halaan dimana terdapat table yang menyajikan pembobotan tipe data yang ada pada $S Q L$. Dan yang terakhir ada menu counting $D B$ yang akan menuju ke halaman dimana akan disajikan sebuah halaman input dengan fungsi input query $S Q L$, yang kemudian query SQL tersebut akan dihitung oleh program dengan menggunakan metrik skala. Adapun Diagram alur kasus penggunaan software ini dapat dilihat pada Gambar 8.

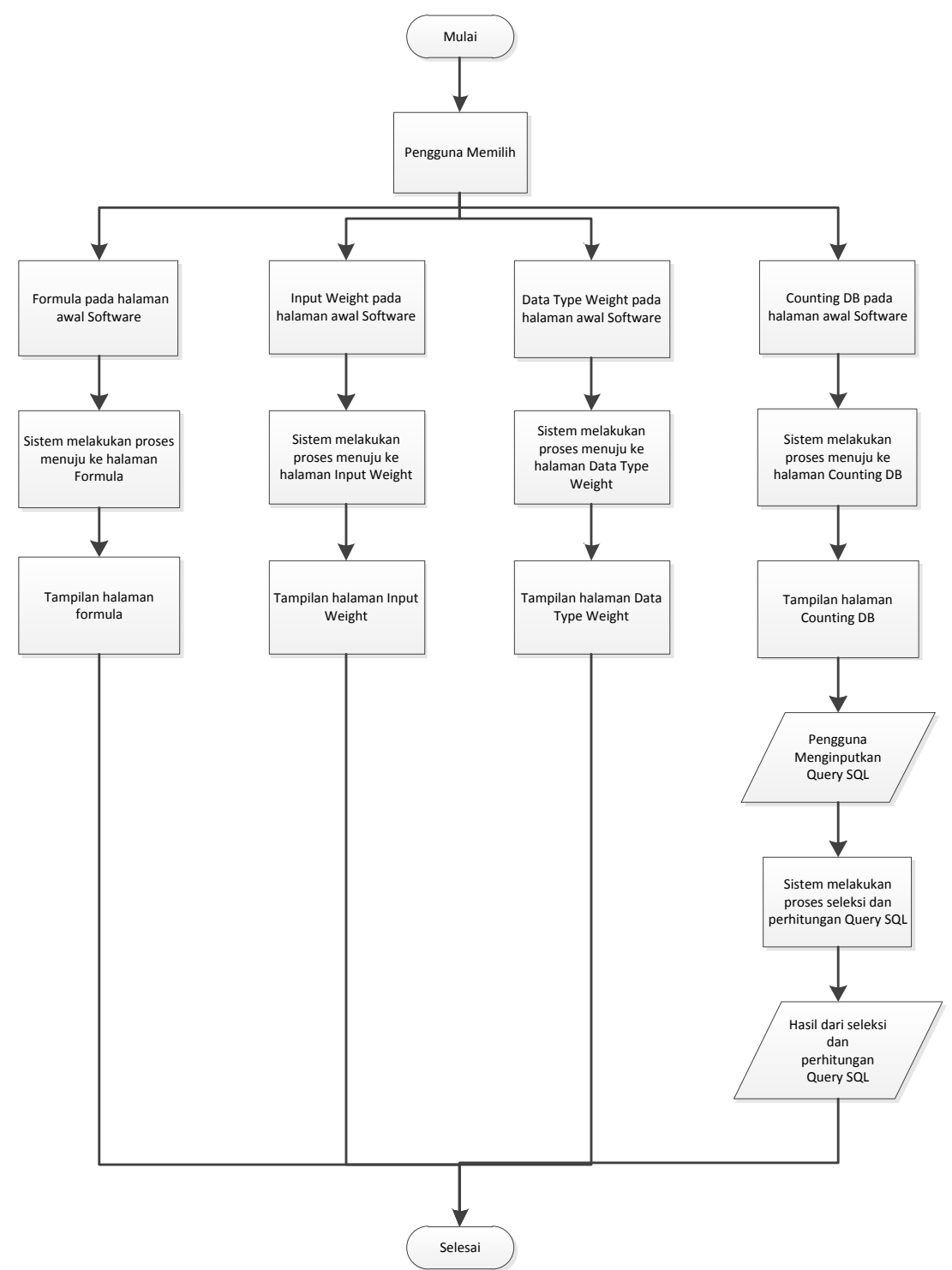

Gambar 8. Diagram alur kasus penggunaan software 
Selanjutnya Query SQL yang diinputkan, akan diproses oleh program. Untuk Diagram alur kasus seleksi query SQL pada software ini dapat dilihat pada Gambar 9.

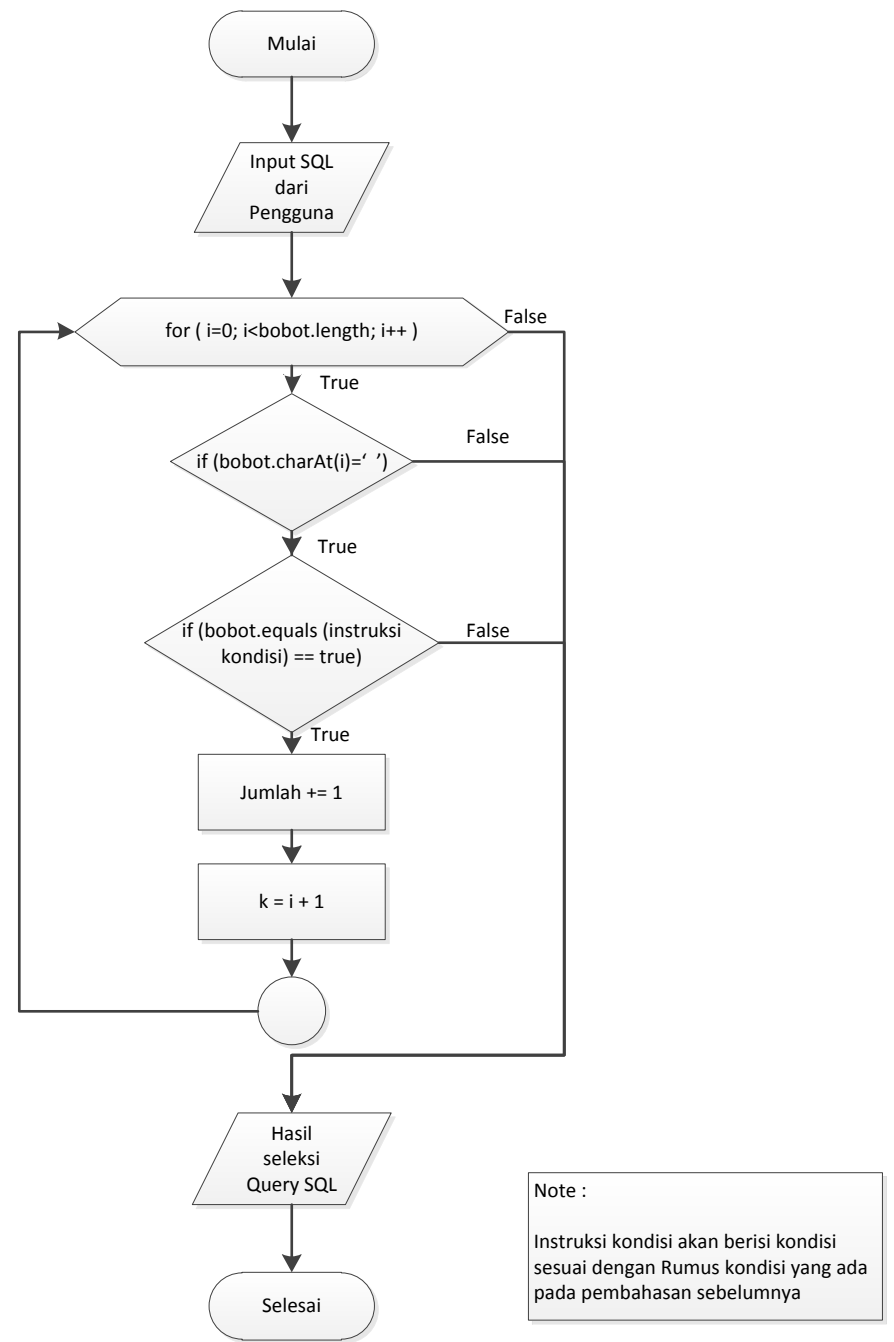

Gambar 9. Diagram alur kasus seleksi query $S Q L$

Setelah SQL di masukkan maka program akan menyeleksi query SQL berdasarkan kondisi yang ada pada rumus kondisi yang terdapat pada tabel 4. Dengan rumus kondisi tersebut akan didapat hasil seleksi query SQL yang pertama, yang akan ditampilkan dalam sebuah kolom guna di eksekusi lebih lanjut.

Tabel 4. Rumus kondisi pada Java

\begin{tabular}{|l|l|}
\hline Metrik & Rumus Kondisi \\
\hline Tabel & “TABLE" \\
\hline Relasi & "REFERENCES" \\
\hline Relasi One to One & "constraint" $=2$ \\
\hline Relasi One to Many & "constraint" $=1$ \\
\hline
\end{tabular}




\begin{tabular}{|c|c|}
\hline Relasi Many to Many & |“constraint" = 2 \&\& "TABLE” + “(“+ " "PRIMARY” > $1+$ + ")" \\
\hline Kolom & “, ” \\
\hline Key & “"PRIMARY”,"FOREIGN”,,SECONDARY”,"INDEX” \\
\hline Tipe Data & $\begin{array}{l}\text { DataType = "tynyint" || "smallint" || "mediumint" || "int" || "bigint" || "float" || } \\
\text { "double" || "real" || "decimal" || "numeric" || "date" || "datetime" || "year" || } \\
\text { "char" || "varchar" || "tinytext" || "text" || "mediumtext" || "longtext" || "bit" || }\end{array}$ \\
\hline Lebar Data & DataType +“("“+ (i) +“")” \\
\hline Primary Key & "PRIMARY" \\
\hline Secondary Key & "SECONDARY" \\
\hline Foreign Key & "FOREIGN" \\
\hline Index & "INDEX" \\
\hline
\end{tabular}

Setelah melewati tahap seleksi kelompok query SQL, hasil dari seleksi tersebut kemudian akan dihitung lagi berdasarkan bobot kelompok. Pengelompokan tersebut berfungsi untuk mendapat bobot tipe data berdasarkan kelompok. Adapun Diagram alur kasus seleksi dan perhitungan query SQL pada software ini dapat dilihat pada Gambar 10.

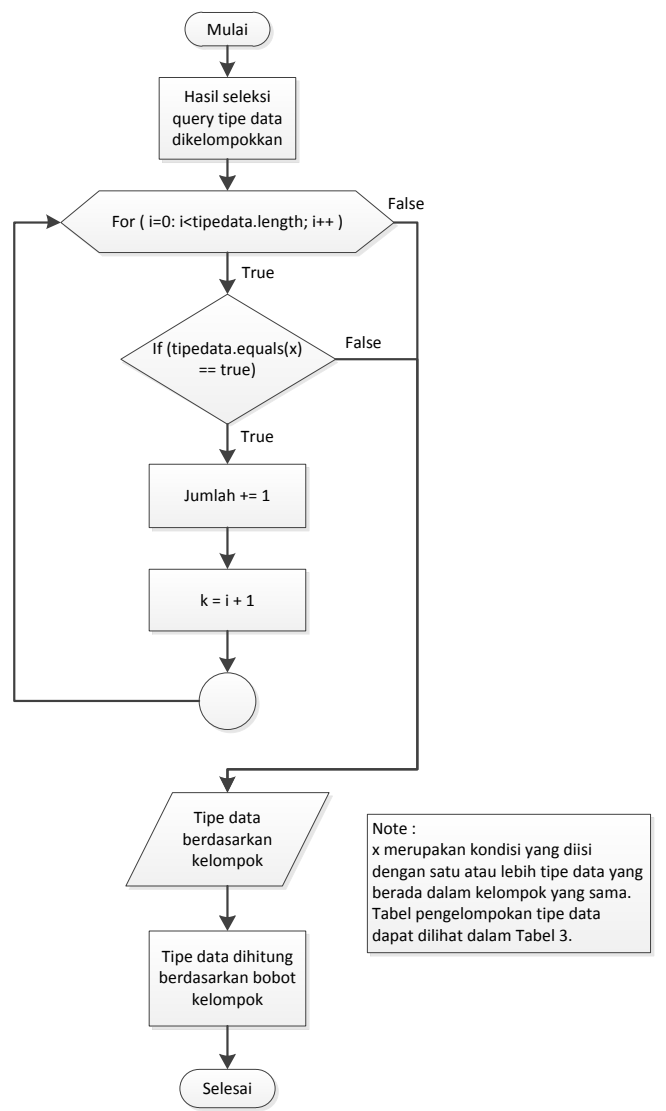

Gambar 10. Diagram alur kasus seleksi dan perhitungan query SQL 
Tahap terakhir dalam alur diagram kasus adalah perhitungan kompleksitas relasional database. Pada tahap ini lebar data akan dihitung secara keseluruhan. System akan merekap keseluruhan metrik yang didapat dan kemudian akan diteruskan menuju perhitungan kompleksitas relasional database. Adapun Diagram alur kasus perhitungan kompleksitas relasional database ini dapat dilihat pada Gambar 11.

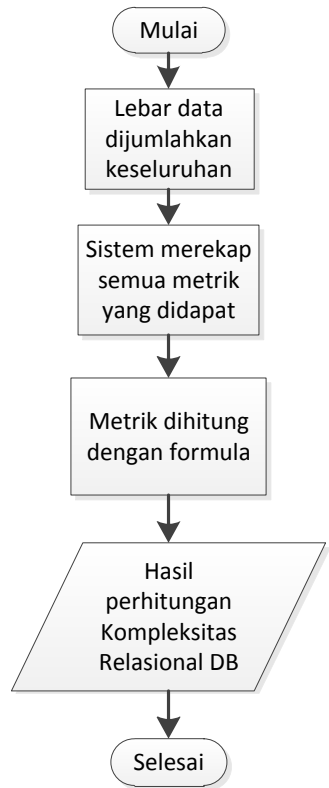

Gambar 11. Diagram alur kasus perhitungan kompleksitas relasional database

\section{Implementasi Studi Kasus}

Pada studi kasus yang dilakukan ini, mengambil dari query SQL yang sudah ada pada Gambar 3, Gambar 4, dan juga Gambar 5 dimana 3 gambar tersebut berisi 3 jenis relasi database yaitu one to one (1:1), one to many (1:M) dan many to many (M:M). Hasil yang didapat dari pengukuran kompleksitas relasional database di atas dengan memperhatikan ketiga jenis relasi menunjukkan hasil yang berbeda-beda antara relasi one to one, one to many dan many to many. Adapun hasil dari pengukuran kompleksitas relasional database dapat di lihat pada Tabel 5.

Tabel 5. Pembahasan dan Hasil Pengukuran Kompleksitas Database Relasional

\begin{tabular}{|c|c|c|c|}
\hline Metrik & M:M & $\mathbf{1 : M}$ & $\mathbf{1 : 1}$ \\
\hline Tabel & 3 & 2 & 9 \\
\hline Kolom & 9 & 7,2 & 7,2 \\
\hline Tipe Data & 7,2 & 153 & 2 \\
\hline Panjang Data & 158 & 2 & 2 \\
\hline Primary Key & 3 & 1 & 0 \\
\hline Foreign Key & 2 & 0 & 0 \\
\hline Secondary Key & 0 & 0 & 2 \\
\hline Index & 0 & 1 & \\
\hline Relasi & 2 & & \\
\hline
\end{tabular}




\begin{tabular}{|c|c|c|c|}
\hline Tipe Relasi & 1,5 & 3,5 & 5 \\
\hline & & & \\
\hline Jumlah & 25,68 & 24,93 & 25,80 \\
\hline
\end{tabular}

\section{KESIMPULAN}

Paper ini mengidentifikasi metrik untuk sebuah database yaitu table, kolom, relasi, lebar data, tipe data, key, primary key, foreign key, secondary key, index, relasi one to one, relasi one to many dan relasi many to many. Dalam perancangan software ini pengukuran kompleksitas relasional database dapat dihitung dengan pengukuran metrik skala. Untuk mengidentifikasi setiap metrik yang ada pada query SQL terdapat beberapa rumus kondisi yang dapat dilihat dalam table 4. Perancangan software ini juga sudah dilengkapi dengan jenis-jenis relasi database yang mana belum ada pada penelitian sebelumnya.

\section{REFERENSI}

[1] E. F. Codd, The Relational Model for Database Management : Version 2. 1990.

[2] C. Calero and M. Piattini, "A FORMAL DEFINITION FOR OBJECT-RELATIONAL DATABASE METRICS," 2003.

[3] M. Piattini, C. Calero, H. Sahraoui, and H. Lounis, “Object-relational database metrics,” pp. 1-21.

[4] T. Idrus, M. A. Yaqin, L. Qomariah, R. Nur, and A. Putri, "Metrik Kompleksitas Desain Database Relasional," vol. 3, no. 1, pp. 90-96, 2020.

[5] S. Abiad, "Software Metrics for Small Database Applications," pp. 866-870, 2000.

[6] V. Trpimirova, "Mile Pavli ć Sveu č ilište u Rijeci , Odjel za informatiku , Adresa , 51000 Rijeka , Croatia Marin Kaluža Neven Vr č ek Fakultet organizacije i informatike, Pavlinska 2, 42000 Varaždin , Croatia Abstract :"

[7] H. Larasati and S. Masripah, "Analisa Dan Perancangan Sistem Informasi Pembelian Grc Dengan Metode Waterfall," None, vol. 13, no. 2, pp. 193-198, 2017.

[8] V. R. Basili, G. Caldiera, and H. D. Rombach, “The goal question metric approach,” vol. 2, pp. 1-10.

[9] A. L. Baroni, C. Calero, and F. Ruiz, "Formalizing object-relational structural metrics Formalizing Object-Relational Structural Metrics," no. May 2014.

[10] K. B. D, "How to do AHP analysis in Excel The Analytical Hierarchy Process - AHP," 2012. 